\title{
Novel Coronavirus and Its Potential Risk of Triggering Inflammatory Disease of the Abdomen during COVID-19: Endoscopic Application
}

\author{
Xianqiang Yu \\ Southeast University, Medical School, Nanjing, China
}

Dear Editor,

We read with great interest an article in your journal about influences of COVID-19 on the application of endoscopic techniques in New York [1]. It is clear that the pandemic has brought great negative impact on endoscopic technology in the diagnosis and treatment of digestive tract diseases. In addition, a growing body of evidence suggests that novel coronavirus can induce abdominal symptoms or directly induce abdominal organ inflammation. From this perspective, gastroenterologists should actively utilize endoscopy to exert its great advantage in digestive tract diseases during this special period. For example, clinicians successfully used endoscopy to remove cotton swabs that had accidentally fallen into the digestive tract during nucleic acid testing [2]. We are, of course, grateful for the potential role of esophagogastroduodenoscopy in the age of minimally invasive surgery in the face of such a strange and frightening process of major public health events.

COVID-19 is an acute infectious disease characterized by respiratory symptoms, yet over time, it has been demonstrated that other systems are affected, including the digestive system. To the best of our knowledge, inflammation of digestive organs such as the appendix, gallbladder, and pancreas are mainly characterized by abdominal

karger@karger.com www.karger.com/ddi

Karger"
(C) 2021 The Author(s)

Published by S. Karger AG, Basel

This is an Open Access article licensed under the Creative Commons Attribution-NonCommercial-4.0 International License (CC BY-NC) (http://www.karger.com/Services/OpenAccessLicense), applicable to the online version of the article only. Usage and distribution for commercial purposes requires written permission. symptoms, which are obviously easily confused with the abdominal symptoms of COVID-19. In particular, viral infection can induce inflammatory diseases in these organs, although viral infection is a rare cause. As far as we know, angiotensin-converting enzyme 2 (ACE2) is the key factor that novel coronavirus can infect cells and further cause disease of related organs [3]. In other words, any organ expressing ACE2 is a potential target organ infected by novel coronavirus. At present, it can be confirmed that the digestive tract organs all have different degrees of ACE2 expression. This suggests that novel coronavirus infection has the potential to directly induce abdominal organ inflammation. Clearly, in the context of COVID-19, a robust diagnostic approach is needed to address gastrointestinal problems.

However, endoscopy plays an irreplaceable role in the determination of novel coronavirus infection in the digestive tract. It can detect digestive tract inflammation and other pathological changes in a very intuitive way. Endoscopy, for example, can be used as the gold standard to determine the etiology of digestive tract lesions. This is impossible for other conventional abdominal examination methods to achieve. However, it needs to be emphasized that the risk of virus transmission in gastrointestinal endoscopy is a problem that cannot be ignored. There- 
fore, the greatest advantages of gastrointestinal endoscopy in this special period can only be played by selecting experienced physicians and conducting standardized operations to prevent the possibility of cross-infection. In conclusion, we should encourage the application of endoscopic technology in the diagnosis and treatment of diseases of the digestive tract during COVID-19, which can not only subtly solve problems of the digestive tract but prevent misdiagnosis and missed diagnosis.

\section{Conflict of Interest Statement}

The author has no conflicts of interest to declare.

\section{Funding Sources}

The author received the Scholarship of Southeast University (No. 189351).

\section{Author Contributions}

Xianqiang Yu completed the design and writing of the article and all the relevant content of the manuscript.

References

1 Annadurai V, Blackett JW, Freedberg D, Hur C, Green PHR, Lebwohl B. Characteristics and outcomes of endoscopies before and during the COVID-19 pandemic in New York. Dig Dis. 2021 Feb 25;1-10.

2 Medas R, Coelho R, Macedo G. An unusual collateral damage of COVID-19 pandemic. Gastrointest Endosc. 2020;92(6):1261-2.
3 Hanley B, Naresh KN, Roufosse C, Nicholson AG, Weir J, Cooke GS, et al. Histopathological findings and viral tropism in UK patients with severe fatal COVID-19: a PostMortem Study. Lancet Microbe. 2020;1(6) e245-53. 